\title{
Synthesis of Ag Nanostructures by Photochemical Reduction Using Citrate-Capped Pt Seeds
}

\author{
Hyeong-Ho Park, ${ }^{1,2}$ Xin Zhang, ${ }^{3}$ Yong-June Choi, ${ }^{1}$ Hyung-Ho Park, ${ }^{1}$ and Ross H. Hill ${ }^{3}$ \\ ${ }^{1}$ Department of Materials Science and Engineering, Yonsei University, 134 Shinchon-dong, Seodaemun-gu, \\ Seoul 120-749, Republic of Korea \\ ${ }^{2}$ Nano Process Division, Patterning Process Department, Korea Advanced Nano Fab Center, \\ Suwon 443-270, Republic of Korea \\ ${ }^{3} 4 \mathrm{D}$ Labs and Department of Chemistry, Simon Fraser University, Burnaby, BC, Canada V5A 1S6
}

Correspondence should be addressed to Hyung-Ho Park, hhpark@yonsei.ac.kr

Received 9 April 2010; Revised 26 May 2010; Accepted 26 July 2010

Academic Editor: Bo Zou

Copyright (c) 2011 Hyeong-Ho Park et al. This is an open access article distributed under the Creative Commons Attribution License, which permits unrestricted use, distribution, and reproduction in any medium, provided the original work is properly cited.

\begin{abstract}
A simple synthesis of Ag nanostructures such as nanorods and nanowires has been demonstrated with citrate-capped Pt seeds. UV-visible spectra and photographs of the synthesized solutions at different UV exposure times showed that the citrate-capped Pt seed played a crucial role in the growth of Ag nanostructures. After UV exposure of the colloidal solution for 60 min, the average diameter, length, and aspect ratio of the Ag nanostructures were about $95 \mathrm{~nm}, 2.1 \mu \mathrm{m}$, and 22, respectively. The photochemical reduction is hypothesized to result from photoelectron transfer from adsorbed citrate to Pt nanoparticle seed allowing Ag ions to form Ag nanostructures. Based on X-ray diffraction spectra and transmission electron microscope images, the synthesized Ag nanostructures were a face-centered cubic single crystal with good purity. These results suggest that the photochemical reduction method can provide Ag nanostructures in the presence of citrate-capped Pt seeds at room temperature for anisotropic Ag products.
\end{abstract}

\section{Introduction}

The field of one-dimensional (1D) nanomaterials research constitutes one of the most important frontiers in materials science. The unusual physicochemical and optoelectronic properties of nanomaterials hold tremendous potential in the synthesis and design of various advanced materials [1]. Among all metals, Ag has attracted a great deal of attention due to the high electrical and thermal conductivities of bulk $\mathrm{Ag}$, which is an important material in many fields [2]. In addition, Ag nanorods and nanowires have recently attracted extensive attention due to their interesting applications, which include photonic crystals [3], infrared polarizers [4], and catalysts [5].

A number of chemical approaches have been extensively explored to process $\mathrm{Ag}$ into 1D materials [2,3]. For instance, a polyol process has been investigated for the preparation of
$\mathrm{Ag}$ nanorods and nanowires, in which the $\mathrm{Ag}$ nanostructures were produced by reducing $\mathrm{AgNO}_{3}$ in ethylene glycol (EG) with the addition of poly(vinyl pyrrolidone) (PVP) [6]. Recently, Sun et al. reported that Pt nanoparticles could serve as seeds for the heterogeneous nucleation and growth of $\mathrm{Ag}$ nanorods and nanowires that were produced in solution via the reduction of $\mathrm{AgNO}_{3}$ with $\mathrm{EG}$ by refluxing at $\sim 160^{\circ} \mathrm{C}$ [2]. In addition, Tsuji et al. reported Ag nanostructures such as nanorods and nanowires by a microwave-polyol method under microwave heating in the presence of Pt seeds [7]. Despite these advances, it is desirable to be able to produce Ag nanostructures at room temperature. Recently, the photochemical reduction method of producing nanomaterials has become an important technique in nanotechnology [8]. It is more convenient and environmental friendly than either electrodeposition using anodic alumina membranes [9] or catalytic CVD growth [10]. Here, we explore a new 
photochemical synthesis of 1-dimensional Ag nanostructures using UV irradiation with citrate-capped Pt nanoparticles, which can be accomplished at room temperature.

\section{Experimental}

Chloroplatinic acid hydrate $\left(\mathrm{H}_{2} \mathrm{PtCl}_{6} \cdot \mathrm{xH}_{2} \mathrm{O}, 99.9 \%\right)$, sodium borohydride $\left(\mathrm{NaBH}_{4}, 98.5 \%\right)$, and sodium citrate tribasic dihydrate $\left(\mathrm{C}_{6} \mathrm{H}_{5} \mathrm{Na}_{3} \mathrm{O}_{7} \cdot 2 \mathrm{H}_{2} \mathrm{O}, 99 \%\right)$ were used for synthesis of citrate-capped $\mathrm{Pt}$ nanoparticle seeds as a catalyst, while silver nitrate $\left(\mathrm{AgNO}_{3}, 99 \%\right)$ and PVP $\left(\left(\mathrm{C}_{6} \mathrm{H}_{9} \mathrm{NO}\right)_{\mathrm{x}}, \mathrm{Mw} \sim 55,000,99 \%\right)$ were used for $\mathrm{Ag}$ nanorods and nanowires. All chemicals were purchased from SigmaAldrich, Inc. Ultrapure deionized water was used to prepare all aqueous solutions for citrate-capped $\mathrm{Pt}$ nanoparticle seeds, Ag nanorods, and nanowires. Pt nanoparticle seeds, $4 \mathrm{~nm}$ in size, capped with citrate, were produced as follows. $1 \mathrm{~mL}$ of $10 \mathrm{mM} \mathrm{NaBH}_{4}$ was added all at once to a $20 \mathrm{~mL}$ solution for a final concentration of $0.47 \mathrm{mM} \mathrm{H}_{2} \mathrm{PtCl}_{6} \cdot \mathrm{xH}_{2} \mathrm{O}$ and $0.47 \mathrm{mM} \mathrm{C}_{6} \mathrm{H}_{5} \mathrm{Na}_{3} \mathrm{O}_{7} \cdot 2 \mathrm{H}_{2} \mathrm{O}$ with vigorous stirring. Stirring was stopped after $30 \mathrm{~s}$ and the resultant solution was aged for $2 \mathrm{~h}$ before use. For synthesis of $\mathrm{Ag}$ nanorods and nanowires, $0.5 \mathrm{~mL}$ of the citrate-capped Pt nanoparticle seed solution was transferred to a $10 \mathrm{~mL}$ vial containing $3 \mathrm{~mL}$ of an aqueous solution of $0.75 \mathrm{mM} \mathrm{AgNO}_{3}$ and $0.50 \mathrm{mM}$ PVP. The solution was irradiated with a $1000 \mathrm{~W}$ mercury arc lamp $\left(\lambda_{\max }=365 \mathrm{~nm}\right)$ at room temperature. UVvisible spectra of the colloidal solutions with different UV exposure times were recorded on a Jasco V-570 UV/vis/NIR spectrophotometer. The samples were prepared by mounting a few drops of the colloidal solutions on a $\mathrm{p}-\mathrm{Si}(100)$ wafer to observe the morphological features of the Ag structures using a scanning electron microscope (SEM). X-ray diffractometer (XRD) samples were prepared on a corning 1737 glass to measure the crystallinity of Ag nanostructures; the XRD used $\mathrm{Cu} k_{\alpha}$ radiation. Particle size distributions of the citratecapped Pt seed solutions with different UV exposure times were measured by a particle size analyzer (PSA) (Malvern Instruments Ltd., Zetasizer Nano Series). Transmission electron microscope (TEM) and electron diffraction studies were performed with a JEOL JEM-4010 microscope operated at $400 \mathrm{kV}$. Samples for TEM were prepared by dispersing a few drops of the colloid solution on a carbon film supported by molybdenum grids.

\section{Results and Discussion}

UV/vis/NIR spectroscopy is a reliable method for detecting the presence of one-dimensional metallic nanostructures $[2,11]$. Specific signature peaks can be used to extract information on the aspect ratio of the nanostructures. UV-visible spectra of the synthesized solutions were measured at different UV exposure times with and without citrate-capped $\mathrm{Pt}$ seeds in the range of 250-900 $\mathrm{nm}$, and the results are given in Figure 1. In the case where citrate-capped Pt seeds were used, UV-visible spectra of the colloidal solutions were different for different UV exposure times, while there was no change in the solution synthesized without citrate-capped Pt seeds.
The introduction of foreign nuclei significantly reduces the nucleation energy and enhances catalysis for the formation of metal nanostructures [12]. In our case, we can infer that citrate-capped $\mathrm{Pt}$ nanoparticle seeds serve as a catalyst for the nucleation and growth of Ag nanostructures. As shown in Figure 1(b), after $15 \mathrm{~min}$ of exposure to UV, the appearance of a plasmon peak at $\sim 410 \mathrm{~nm}$ indicated the formation of $\mathrm{Ag}$ nanostructures $[13,14]$. It is well known that the UV-visible absorption spectrum of Ag nanostructures depends on the size of the nanostructures, that is, the wavelength at maximum absorption $\left(\lambda_{\max }\right)$ increases as the aspect ratio of the nanostructure increases [14]. Increases in aspect ratio are apparent with increasing exposure time, since, for UV exposure of the colloidal solutions for 15 , 45 , and $60 \mathrm{~min}$, the values of $\lambda_{\max }$ were 407,420 , and $450 \mathrm{~nm}$, respectively. In the spectrum corresponding to UV exposure for $60 \mathrm{~min}$, a shoulder peak around $350 \mathrm{~nm}$ becomes more apparent, as a result of increasing aspect ratio of Ag nanostructures. The absorption peak at $350 \mathrm{~nm}$ can be attributed to the plasmon response peak from the longitudinal vibration in Ag nanowires [15]. In the case of polyol processes, Ag nanowires were obtained only under heat treatment at $\sim 160^{\circ} \mathrm{C}$ for $40 \mathrm{~min}[2,16]$. However, here, UV exposure of the colloidal solutions for $60 \mathrm{~min}$ at room temperature is sufficient for the growth of $\mathrm{Ag}$ nanowires. In addition, the role of UV light was checked to follow the advance of the silver salt reduction in the presence of citratecapped Pt nanoparticle seeds at room temperature without UV irradiation according to storage in various times as shown in Figure 1(c). There was no change in the UV-visible spectra of solutions synthesized without UV irrdiation. So, we can deduce that during UV irradiation the citrate-capped $\mathrm{Pt}$ nanoparticle seeds played a crucial role for the formation of Ag nanostructures.

The morphologies and sizes of synthesized products irradiated by UV exposure for 45 and 60 min were observed using an SEM. In our case, after UV exposure of the colloidal solution for $45 \mathrm{~min}$, we observed the formation of Ag nanoparticles and nanorods as shown in Figure 2(a). After UV exposure for $60 \mathrm{~min}$, Figure 2(b), Ag nanoparticles, nanorods, and nanowires were formed. Nanorods and nanowires can be distinguished from their aspect ratio, 220 and $>20$, respectively $[7,14]$. In polyol processes, the evolution of Ag nanostructures went from Ag nanoparticles and nanorods to $\mathrm{Ag}$ nanorods and nanowires with various heating times $[2,16]$. Similarly, the evolution of Ag nanostructures formed by photochemical reduction went from a 0 dimension to a 1 dimension morphology according to the UV exposure time. Analysis of SEM micrographs indicates that the product UV irradiated for 45 min contains mainly spherically shaped Ag nanoparticles that have diameters of about $86 \mathrm{~nm}$. In the case of the product UV irradiated for $60 \mathrm{~min}$, the average diameter, length, and aspect ratios of the $\mathrm{Ag}$ nanostructures are about $95 \mathrm{~nm}, 2.1 \mu \mathrm{m}$, and 22, respectively. From the results of UV-Visible spectra (Figure 1), the symmetric absorption peak implies that the size distribution of the Ag nanoparticles is narrow and the asymmetric absorption peak implies that wire-shaped $\mathrm{Ag}$ nanostructures, that is, long $\mathrm{Ag}$ nanowires grow due to an 


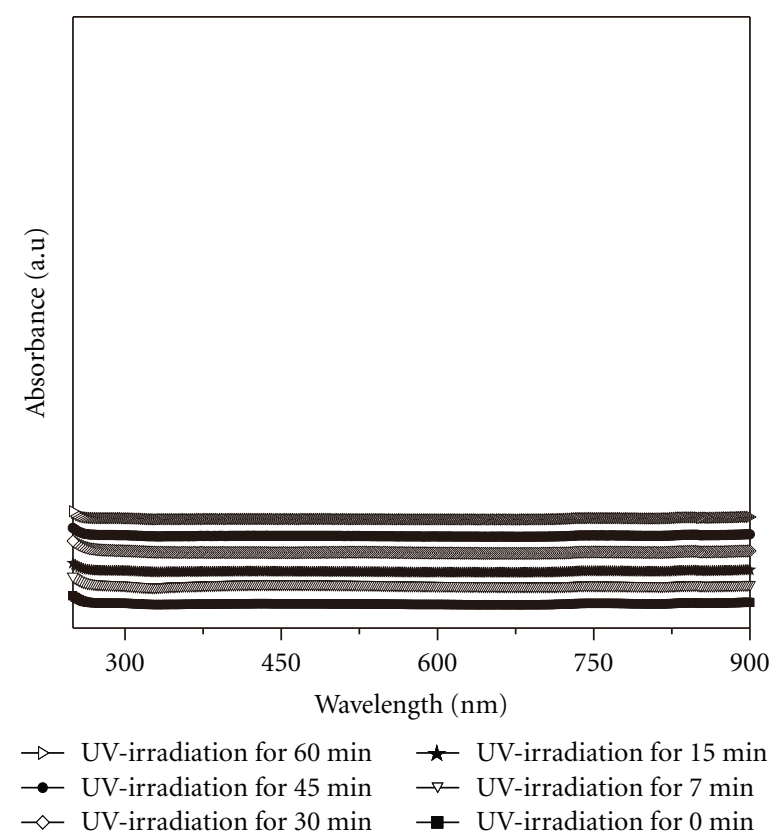

(a)

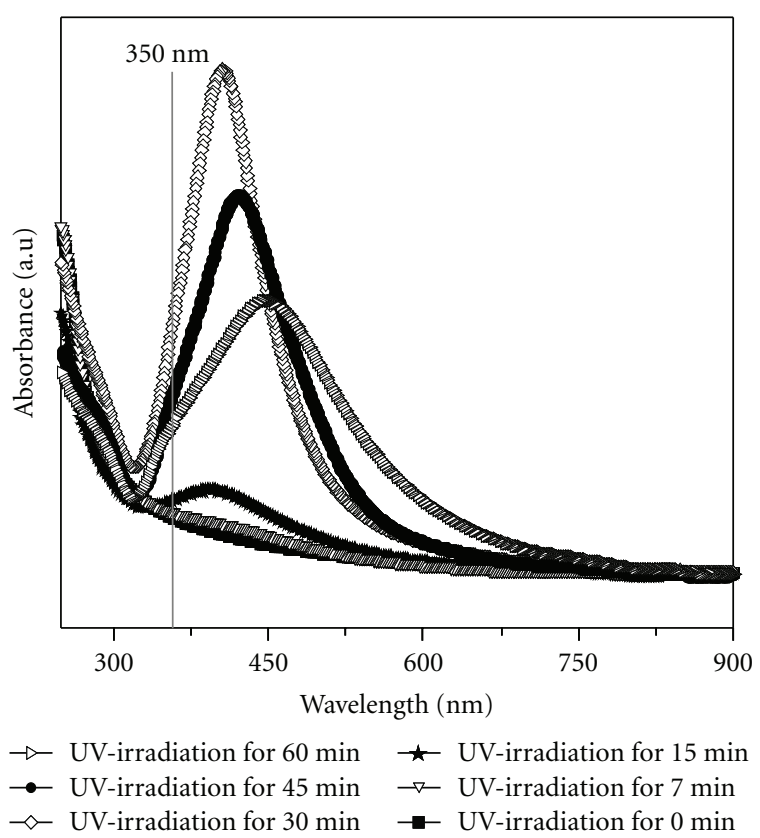

(b)

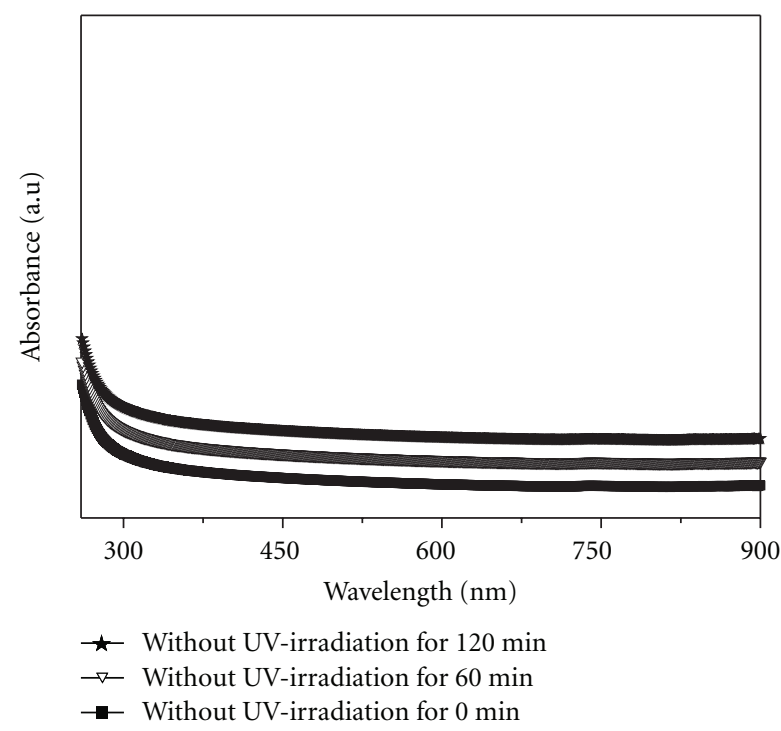

(c)

FIgURe 1: UV-visible absorption spectra of the synthesized solutions: (a) without Pt seeds, (b) with Pt seeds, and (c) with Pt seeds and without UV irradiation.

extra absorption peak around $350 \mathrm{~nm}$. In this experiment, the main photoproduct is a mixture of Ag nanoparticles until for $45 \mathrm{~min}$ of UV irradiation, however, after $60 \mathrm{~min}$, additional photoproduct is achieved in an anisotropic growth for the Ag nanorods/nanowires as shown in Figure 2(b).

XRD spectra of the product UV irradiated for $60 \mathrm{~min}$ and the standard powder pattern of Ag (Joint Committee on Powder Diffraction Standards (JCPDS) File 04-0783) are shown in Figure 3. All the peaks are indexed with a facecentered cubic (fcc) single crystal, which indicates that the products were Ag, with good purity. The average crystallite size of the product UV irradiated for $60 \mathrm{~min}$ was calculated from the XRD line broadening using the Scherrer equation [17]:

$$
B=\frac{0.93 \lambda}{(L \cos \theta)},
$$

where $\lambda$ is the wavelength of the incident $\mathrm{X}$-rays $(\lambda=$ $1.54178 \AA$ ), $L$ is the full width at half maximum of the (111) diffraction, and $\theta$ is the angle of diffraction. The average crystallite size of the product UV irradiated for 60 min was $78.9 \mathrm{~nm}$, which is relatively close to the average diameter $(95 \mathrm{~nm})$ of the Ag nanostructures as shown in the SEM image. 


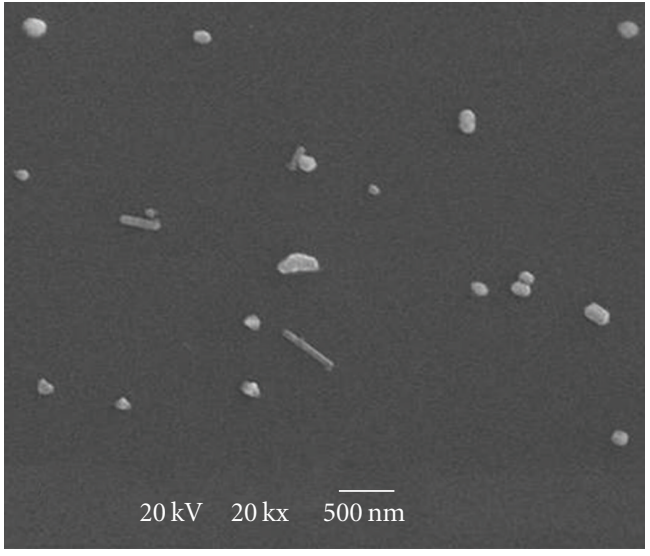

(a)

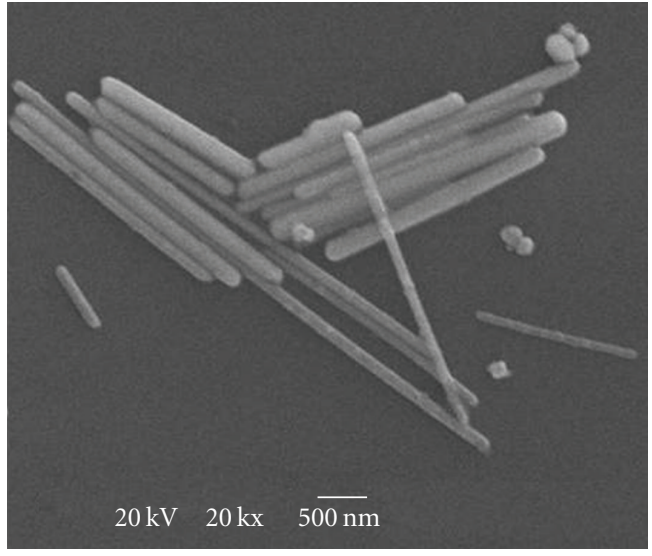

(b)

FIGURE 2: SEM micrographs of as-synthesized samples of Ag nanostructures after UV exposure for (a) 45 and (b) 60 min.

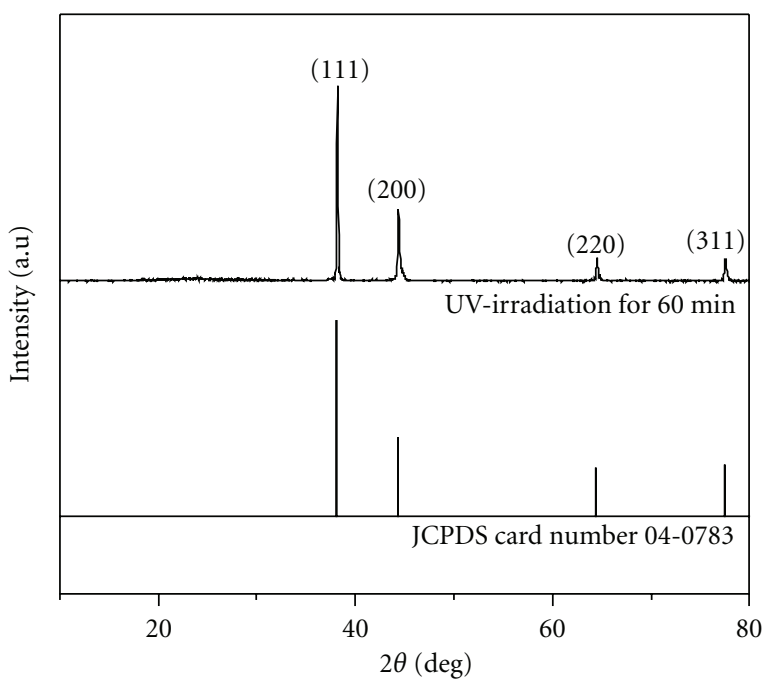

FIgURE 3: XRD spectra of Ag nanostructures irradiated by UV for 60 min and simulated results of Ag powder from JCPDS 04-0783.

Figure 4(a) exhibits a low-magnification TEM image of a $\mathrm{Ag}$ nanorod with a diameter of about $100 \mathrm{~nm}$. Furthermore, selected area electron diffraction (SAED) was used to confirm the high crystallinity of the synthesized Ag nanorods. Figure 4(b) shows the typical SAED pattern of a Ag nanorod, which was obtained by focusing the electronic beam along the [011] zone axis of an individual nanorod. Judging from the results of Figures 4(b) and 4(c), the synthesized Ag nanorods have predominantly grown along the [100] direction. From the high-resolution TEM (HRTEM) image shown in Figure 4(d), the values of the interplanar spacing of $\{200\}$ and $\{111\}$ planes were 0.205 and $0.231 \mathrm{~nm}$, respectively, in good agreement with the lattice spacing of fcc Ag. This result revealed that the Ag nanostructures formed by photochemical reduction at room temperature were singlecrystalline with a well-resolved interference fringe spacing. It can be recalled from the results of UV-Visible spectra, a red-shift of the wavelength at maximum absorption can be inferred due to either the increment of aspect ratio of $\mathrm{Ag}$ nanostructures or uniform growth of Ag particles. Analysis of SEM and TEM micrographs indicates that the product UV irradiated for 45 min contains mainly spherically shaped Ag nanoparticles/nanorods, and the product UV irradiated for 60 min consists of Ag nanoparticle, nanorods and nanowires. A red shift of the wavelength at $\lambda_{\max }$ would be mainly due to the increment of aspect ratio of Ag nanostructures. Also, as indicated in the UV-visible spectra in Figure 1(a), Ag nanostructures were not formed in the solution without citrate-capped Pt nanoparticle seeds. Therefore, the citratecapped Pt nanoparticle seed played a crucial role as a catalyst for the formation of $\mathrm{Ag}$ nanostructures.

The mechanism for the formation of Ag nanostructures by a photochemical reduction in the presence of $\mathrm{Pt}$ seeds has not yet been reported; based on our experimental data, we propose a mechanism here. Munro et al. [18] reported a mechanism for the reduction of $\mathrm{Ag}^{+}$by citrate through a thermal approach. In their paper, a model was proposed for the interaction and orientation of citrate ions on the surface of Ag nanoparticles. Redmond et al. [19] reported a mechanism for the reduction of $\mathrm{Ag}^{+}$by citrate through a photochemical approach. In both of abovementioned mechanisms, heating [18], or photon excitation [19], results in the donation of electrons from citrate ions to $\mathrm{Ag}$ nanoparticle seeds, leading to both the formation of $\mathrm{Ag}$ nanoparticles with extra electrons and the decomposition of citrate ions. The Ag nanoparticles with extra electrons then become the reducing source for $\mathrm{Ag}^{+}$. The decomposition of citrate ions in the photochemical approach has been described through the following reaction $[19,20]$.

$$
\text { Citrate } \stackrel{h v}{\longrightarrow} \text { acetone-1,3-dicarboxylate }+\mathrm{CO}_{2}+2 e^{-}
$$

In order to confirm the decomposition of citrate on $\mathrm{Pt}$ nanoparticle seeds, solutions containing only citrate-capped 


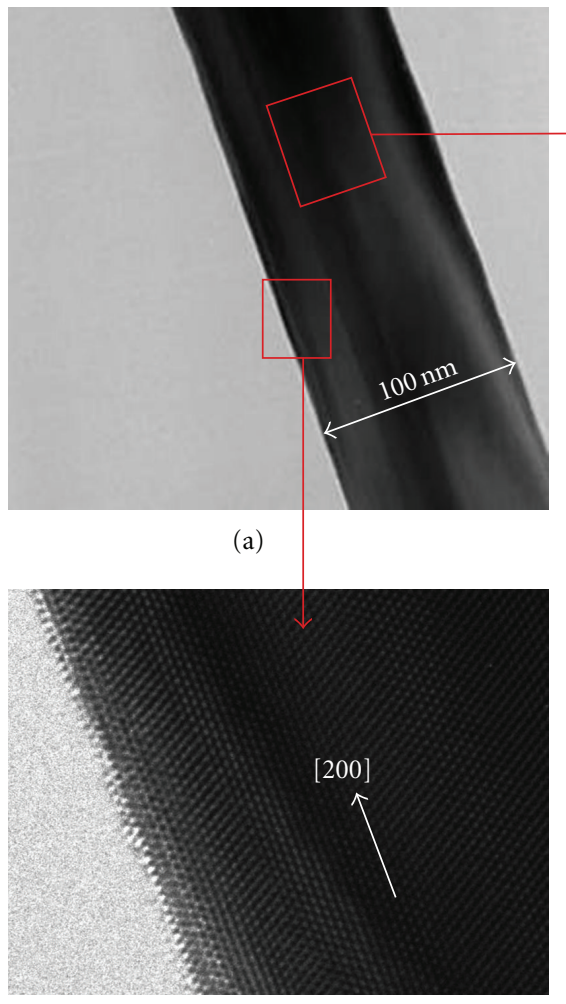

(c)

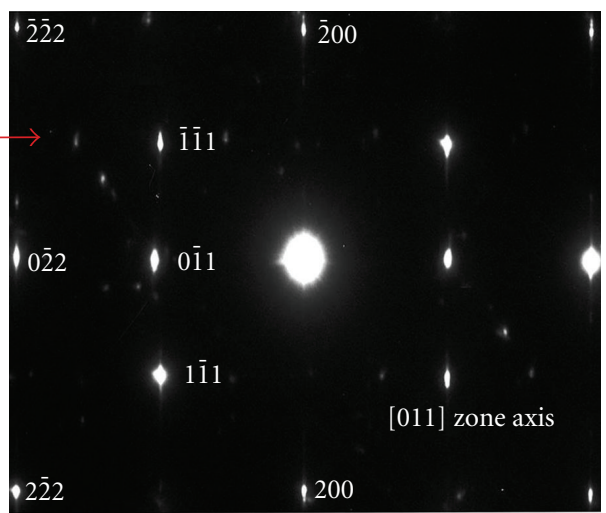

(b)

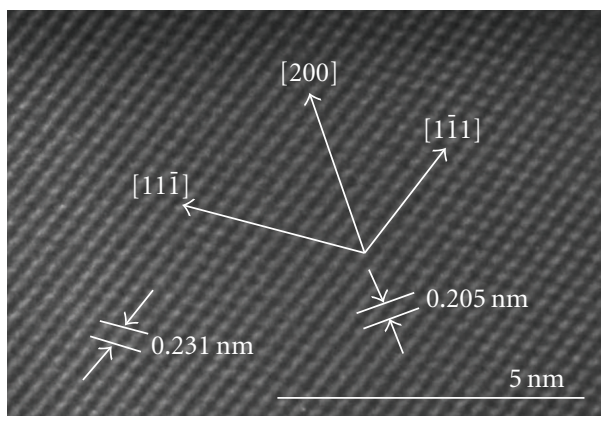

(d)

FIgURE 4: (a) Low magnification, (b) electron diffraction pattern, and (c, d) high-magnification TEM micrographs of a Ag nanorod synthesized by UV exposure for $60 \mathrm{~min}$.

Pt nanoparticles were irradiated by UV light at various exposure times. At UV exposure times of $0,15,30,45$, and $60 \mathrm{~min}$, the average particle sizes were obtained by using PSA as $4.23,21.13,21.67,36.43$, and $76.83 \mathrm{~nm}$, respectively. This result means that the citrate on Pt nanoparticle seeds decomposed during photochemical reduction. As a result, the average particle size of Pt nanoparticle seeds increased with increasing UV exposure time.

As shown in (2), acetone-1,3-dicarboxylate, carbon dioxide, and electrons are formed due to the photochemical excitation of citrate. Nucleophilic adsorption of the carboxylic anions causes the citrate to bind onto the surface of $\mathrm{Ag}$ nanoparticles. Upon absorption of a photon, the carboxylic groups directly attached to Ag nanoparticles presumably undergo ligand to metal charge transfer, where the electrons directly transfer to the Ag nanoparticles [19, 20]. These Ag nanoparticles, acting as a reactive electron storage and transfer medium, make it more likely to reduce $\mathrm{Ag}^{+}$on their surface [20].

In our case, the Pt nanoparticle seeds are believed to play a role similar to that of the Ag nanoparticle seeds used in the above reports. Therefore, we propose the following equation to describe the photochemical reaction of citrate in the presence of $\mathrm{Pt}$ nanoparticle seeds as shown in Figure 5.

$$
\begin{gathered}
\text { Citrate-nPt } \stackrel{h v}{\longrightarrow} \text { acetone-1,3-dicarboxylate } \\
+\mathrm{CO}_{2}+\mathrm{H}^{+}+\mathrm{nPt}^{2^{-}}
\end{gathered}
$$

Upon the absorption of a photon, the adsorbed citrate undergoes a ligand to metal charge transfer, resulting in a citrate radical and a $\mathrm{Pt}$ seed with an extra electron. The unstable citrate radical undergoes further photochemical and thermal decomposition, leading to the formation of an acetone-1,3-dicarboxylate, a $\mathrm{CO}_{2}$, and a $\mathrm{H}^{\bullet}$ radical. The $\mathrm{H}^{\bullet}$ radical is in close proximity to the $\mathrm{Pt}$ seed and will very likely encounter the Pt seed, resulting in the release of an electron to the $\mathrm{Pt}$ seed and the formation of an $\mathrm{H}^{+}$. The resultant $\mathrm{Pt}$ seed with extra electrons, $\mathrm{nPt}^{2-}$, can now reduce the $\mathrm{Ag}^{+}$it encounters. It has been proposed $[21,22]$ that $\mathrm{H}_{2} \mathrm{O}$ could also be decomposed by UV irradiation as shown below.

$$
\mathrm{H}_{2} \mathrm{O} \stackrel{h v}{\longrightarrow} \mathrm{H}^{\bullet}+\mathrm{OH}^{\bullet}
$$

The reactive $\mathrm{H}^{\bullet}$ and $\mathrm{OH}^{\bullet}$ radicals can be the reducing source for $\mathrm{Ag}^{+}$as well. However, we believe (4) is not dominant in our case.

For a $\mathrm{Ag}^{+}$ion, electron capture happens when the ion encounters a seed with extra electrons. $\mathrm{Ag}^{+}$ions can encounter the Pt nanoparticle seeds as shown below.

$$
\begin{aligned}
& \mathrm{nPt}^{2-}+\mathrm{Ag}^{+} \longrightarrow(\mathrm{nPt}-\mathrm{Ag})^{-} \\
& (\mathrm{nPt}-\mathrm{Ag})^{-}+\mathrm{Ag}^{+} \longrightarrow \mathrm{nPt}-2 \mathrm{Ag}
\end{aligned}
$$



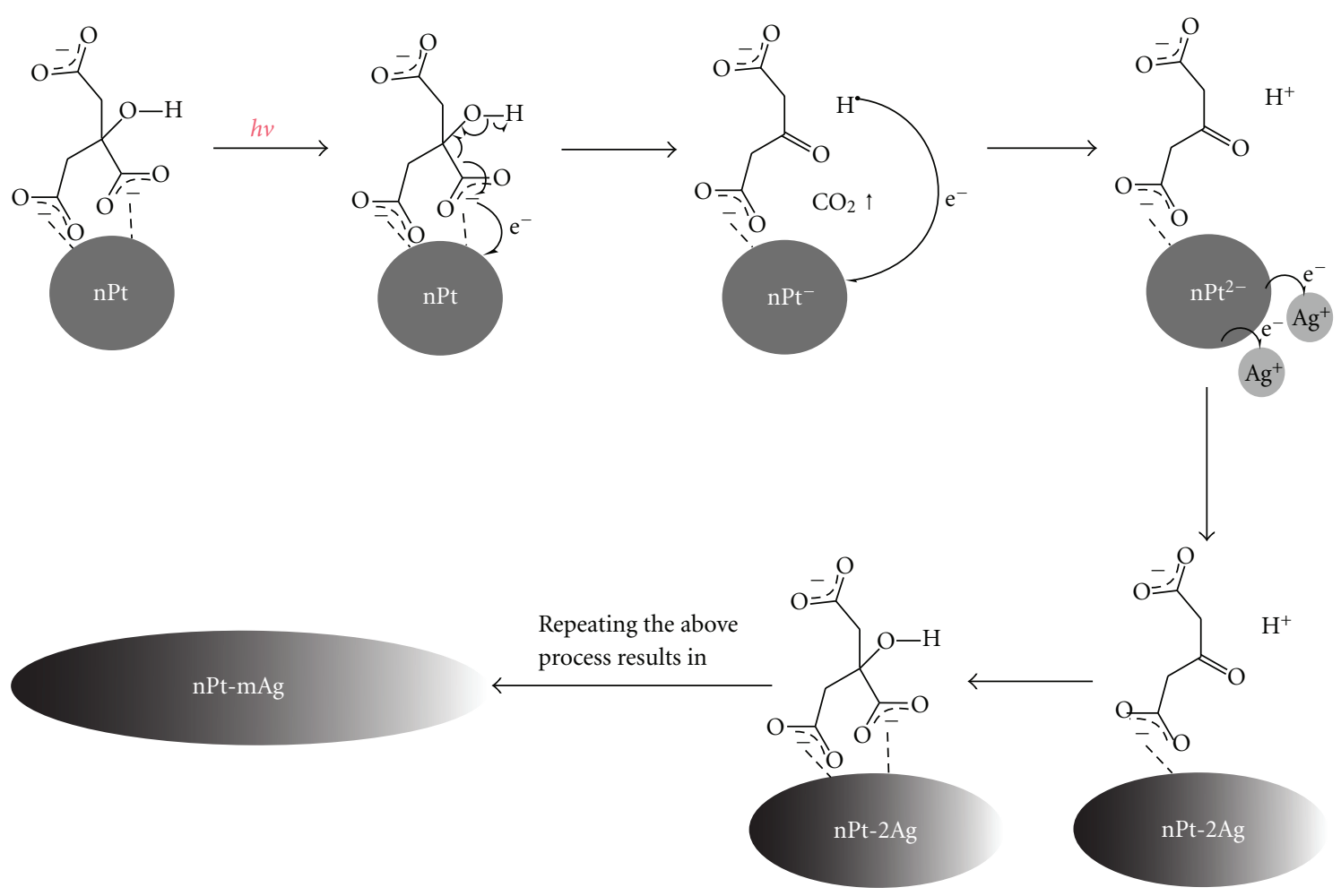

FIGURE 5: A plausible mechanism for the synthesis of Ag nanostructures formed by a photochemical reduction.

The process described by (3), (5), and (6) repeats continuously during UV irradiation, resulting in the growth of Ag on the Pt seeds, nPt-mAg in Figure 5. Although further evidence needs to be obtained, we suggest the following process for the formation of $\mathrm{Ag}$ nanowires. During the growth of $\mathrm{Ag}$ nanostructures, once the reduced $\mathrm{Ag}$ atoms bind to the surface of a Pt seed, the Pt seed becomes a particle partially coated with Ag. Due to the fact that Pt has a much higher work function than $\mathrm{Ag}$, the coated $\mathrm{Ag}$ on $\mathrm{Pt}$ seed is more reducing than the Pt seed [23]. This means that $\mathrm{Ag}^{+}$ions are more likely to be reduced at the coated $\mathrm{Ag}$ on the polar particle. Also, due to the assistance of rod-like PVP micelles [24], Ag nanostructure growth in one direction becomes possible.

\section{Conclusion}

A simple approach to the synthesis of Ag nanostructures such as nanorods and nanowires by a photochemical reduction at room temperature was demonstrated. Citrate-capped $\mathrm{Pt}$ nanoparticle seeds played a crucial role as a catalyst for the growth of Ag nanostructures. From the results of UVvisible spectra, photographs of the synthesized solution, SEM and TEM images, we can deduce the synthesis of singlecrystalline Ag nanorods and nanowires by a photochemical reduction at room temperature. These experiments helped to outline the mechanism of $\mathrm{Ag}$ nanostructure formation using citrate-capped Pt nanoparticle seeds prepared by photochemical reduction. Our Ag nanostructures are anticipated to have important applications in electronics such as the miniaturization of electronic devices and the improvement of ultralarge-scale integrated circuits.

\section{Acknowledgments}

This paper was supported by Nano R\&D program through the National Research Foundation of Korea funded by the Ministry of Education, Science and Technology (20090082604). The experiments at the PLS were supported in part by the MOST and the POSTECH.

\section{References}

[1] A. P. Alivisatos, "Semiconductor clusters, nanocrystals, and quantum dots," Science, vol. 271, no. 5251, pp. 933-937, 1996.

[2] Y. Sun, B. Gates, B. Mayers, and Y. Xia, "Crystalline silver nanowires by soft solution processing," Nano Letters, vol. 2, no. 2, pp. 165-168, 2002.

[3] X. Hu and C. T. Chan, "Photonic crystals with silver nanowires as a near-infrared superlens," Applied Physics Letters, vol. 85, no. 9, pp. 1520-1522, 2004.

[4] Y. T. Pang, G. W. Meng, Q. Fang, and L. D. Zhang, "Silver nanowire array infrared polarizers," Nanotechnology, vol. 14, no. 1, pp. 20-24, 2003.

[5] R. J. Chimentão, I. Kirm, F. Medina et al., "Different morphologies of silver nanoparticles as catalysts for the selective oxidation of styrene in the gas phase," Chemical Communications, vol. 10, no. 7, pp. 846-847, 2004.

[6] Y. Gao, P. Jiang, D. F. Liu et al., "Synthesis, characterization and self-assembly of silver nanowires," Chemical Physics Letters, vol. 380, no. 1-2, pp. 146-149, 2003. 
[7] M. Tsuji, Y. Nishizawa, M. Hashimoto, and T. Tsuji, "Syntheses of silver nanofilms, nanorods, and nanowires by a microwave-polyol method in the presence of pt seeds and polyvinylpyrrolidone," Chemistry Letters, vol. 33, no. 4, pp. 370-371, 2004.

[8] K. Esumi, T. Matsumoto, Y. Seto, and T. Yoshimura, "Preparation of gold-, gold/silver-dendrimer nanocomposites in the presence of benzoin in ethanol by UV irradiation," Journal of Colloid and Interface Science, vol. 284, no. 1, pp. 199-203, 2005.

[9] R.-L. Zong, J. Zhou, Q. Li et al., "Synthesis and optical properties of silver nanowire arrays embedded in anodic alumina membrane," Journal of Physical Chemistry B, vol. 108, no. 43, pp. 16713-16716, 2004.

[10] Z. Yu, Z. Yang, S. Wang et al., "Growth of GaN nanorods via Au catalyst-assisted CVD," Chemical Vapor Deposition, vol. 11, no. 10, pp. 433-436, 2005.

[11] Y. Gao, P. Jiang, L. Song et al., "Growth mechanism of silver nanowires synthesized by polyvinylpyrrolidone-assisted polyol reduction," Journal of Physics D, vol. 38, no. 7, pp. 10611067, 2005.

[12] D. Poondi and J. Singh, "Synthesis of metastable silver-nickel alloys by a novel laser-liquid-solid interaction technique," Journal of Materials Science, vol. 35, no. 10, pp. 2467-2476, 2000.

[13] C.-S. Hong, H.-H. Park, S.-J. Wang, J. Moon, H.-H. Park, and R. H. Hill, "Formation of photoresist-free patterned $\mathrm{ZnO}$ film containing nano-sized Ag by photochemical solution deposition," Applied Surface Science, vol. 252, no. 21, pp. 7739$7742,2006$.

[14] C. J. Murphy and N. R. Jana, "Controlling the aspect ratio of inorganic nanorods and nanowires," Advanced Materials, vol. 14, no. 1, pp. 80-82, 2002.

[15] D. Zhang, L. Qi, J. Yang, J. Ma, H. Cheng, and L. Huang, "Wet chemical synthesis of silver nanowire thin films at ambient temperature," Chemistry of Materials, vol. 16, no. 5, pp. 872876, 2004.

[16] Y. Sun, Y. Yin, B. T. Mayers, T. Herricks, and Y. Xia, "Uniform silver nanowires synthesis by reducing $\mathrm{AgNO}_{3}$ with ethylene glycol in the presence of seeds and poly(vinyl pyrrolidone)," Chemistry of Materials, vol. 14, no. 11, pp. 4736-4745, 2002.

[17] A. L. Patterson, "The scherrer formula for X-ray particle size determination," Physical Review, vol. 56, no. 10, pp. 978-982, 1939.

[18] C. H. Munro, W. E. Smith, M. Garner, J. Clarkson, and P. C. White, "Characterization of the surface of a citrate-reduced colloid optimized for use as a substrate for surface-enhanced resonance raman scattering," Langmuir, vol. 11, no. 10, pp. 3712-3720, 1995.

[19] P. L. Redmond, X. Wu, and L. Brus, "Photovoltage and photocatalyzed growth in citrate-stabilized colloidal silver nanocrystals," Journal of Physical Chemistry C, vol. 111, no. 25, pp. 8942-8947, 2007.

[20] M. Maillard, P. Huang, and L. Brus, "Silver nanodisk growth by surface plasmon enhanced photoreduction of adsorbed $\left[\mathrm{Ag}^{+}\right]$," Nano Letters, vol. 3, no. 11, pp. 1611-1615, 2003.

[21] K. Mallick, M. J. Witcomb, and M. S. Scurrell, "Polymer stabilized silver nanoparticles: a photochemical cynthesis route," Journal of Materials Science, vol. 39, no. 14, pp. 44594463, 2004.

[22] Y. Zhou, L. Hao, Y. Hu, Y. Zhu, and Z. Chen, "Synthesis of nanowires and coral-shaped nanostructures of $\mathrm{Ag}$ by an ultraviolet photo-reduction technique at room temperature," Chemistry Letters, no. 11, pp. 1192-1193, 2001.
[23] B. Pellegrini, "Properties of silicon-metal contacts versus metal work-function, silicon impurity concentration and bias voltage," Journal of Physics D, vol. 9, no. 1, pp. 55-68, 1976.

[24] D. Chen and L. Gao, "Large-scale growth and end-to-end assembly of silver nanorods by PVP-directed polyol process," Journal of Crystal Growth, vol. 264, no. 1-3, pp. 216-222, 2004. 

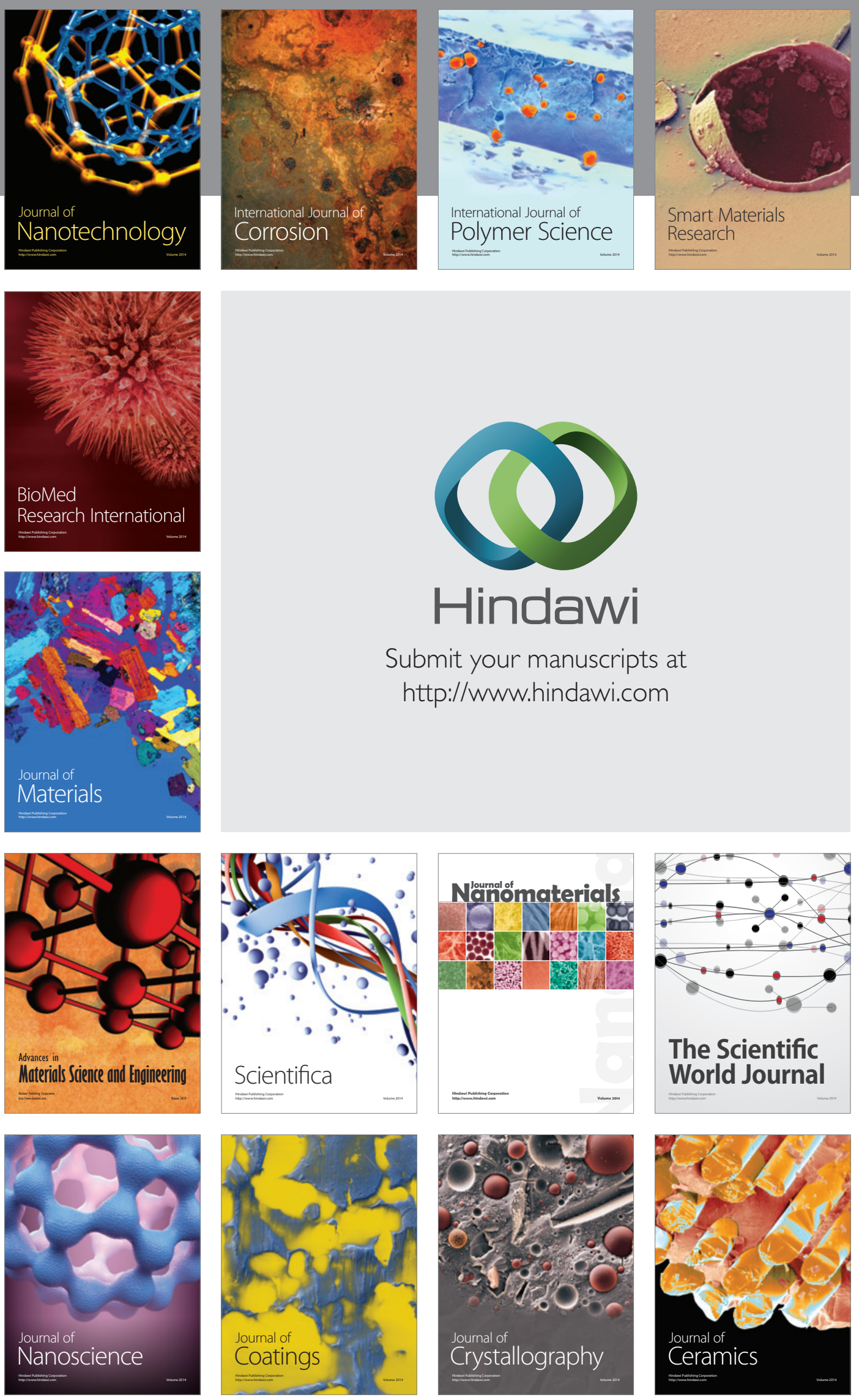

The Scientific World Journal

Submit your manuscripts at

http://www.hindawi.com

\section{World Journal}

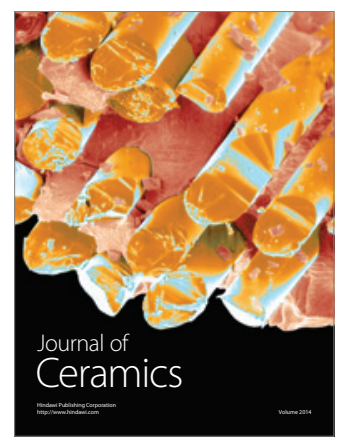

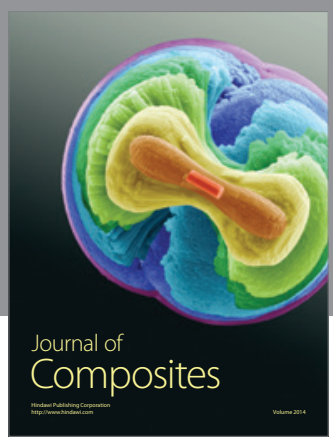
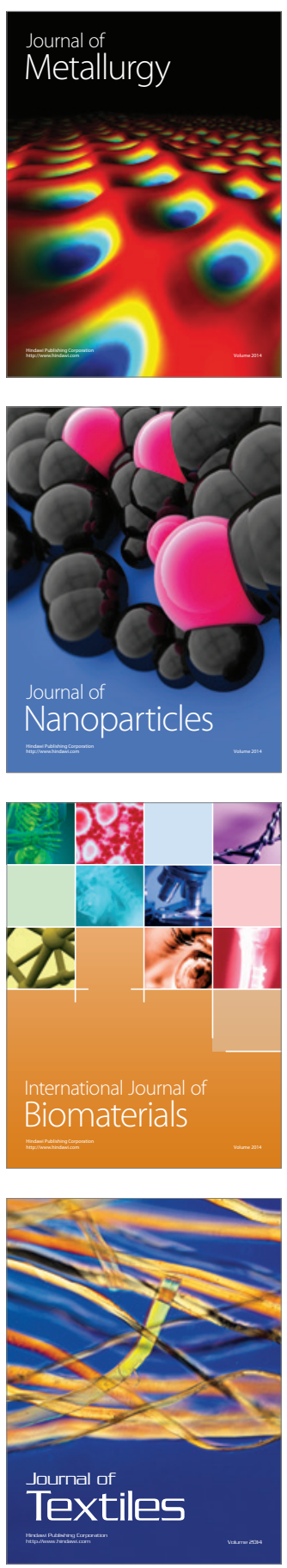